\title{
CORE COMPETENCIES TO USE CLOUD COMPUTING SERVICES
}

\author{
M. Yordanov, A. Yordanova, L. Yordanova* \\ Faculty of Technics and Technologies, Trakia University, Stara Zagora, Bulgaria \\ Faculty of Mathematics and Informatics, Plovdiv University, Plovdiv, Bulgaria \\ Faculty of Economics, Trakia University, Stara Zagora, Bulgaria
}

\begin{abstract}
Cloud computing services form an environment, what the business organizations should use in efficient way. For this the important role belongs to the people working in the companies. Their competencies in cloud computing usage are needed as one of the main tendencies in ICT for 2015 is the increasing the implementation of clouds in all business activities.

The aim of current work is to research, analyze and present main groups of user's competencies in the area of cloud computing. A survey is organized for determining the level of competencies and knowledge of students in Trakia University about cloud computing services. The conclusions and recommendations are made concerning the learning topics and teaching subjects.
\end{abstract}

Key words: Cloud computing, Cloud computing competencies, user profile

\section{INTRODUCTION}

Last five years something important happened in business world. Internet became an innovative business environment with significant role for the future development. The companies which don't realize how important Internet possibilities and services are lose their positions and clients. The Cloud computing services form an environment, what the business organizations should use in efficient way. Crucial role in this process belongs to the companies' stuff. Their competencies in cloud computing usage are needed as one of the main tendencies in ICT for 2015 is the increasing the implementation of clouds in all business activities. (1) Data shows that only $8 \%$ of companies in Bulgaria use cloud computing. (2) It is logical to think about rest $92 \%$ of the companies which will start with cloud computing. The situation with individual users in Bulgaria is similar $-11 \%$ of Internet users use regularly cloud services for file storage. (3) Rest $89 \%$ have to learn about diversity of cloud services.

The goal of the current work is to research, analyze and present main groups of user's competencies in the area of cloud computing.

${ }^{*}$ Correspondence to: Lina Yordanova, Trakia University, Faculty of Economics, Stara Zagora, Bulgaria,lina@uni-sz.bg
The determination of the level of competencies and knowledges of students in Trakia University about cloud computing services is also important for us.

To achieve these two goals we had to solve some tasks like following:

1. Research on:

- Cloud computing;

- Skills and knowledges in the area.

2. Creating a quiz on Cloud computing;

3. Organization of the performance of the quiz and collecting data;

4. Processing data via SPSS.

\section{CLOUD COMPUTING}

Long passed the time when the term "cloud computing" was associated with the weather forecast. Now we imagine this technology as an opportunity to synchronize data and information between all our devices, to cowork with colleagues, to share information different ways and etc. The places of data storage is somewhere in "the cloud", as ICT specialists explain to other people. Things are much more serious, complicated and they are associated with different patterns of use of Web services, available through Internet Web destination. Such as Software as a Service (SaaS), Platform as a Service (PaaS) or Infrastructure as a Service (IaaS). $(4,5)$ 


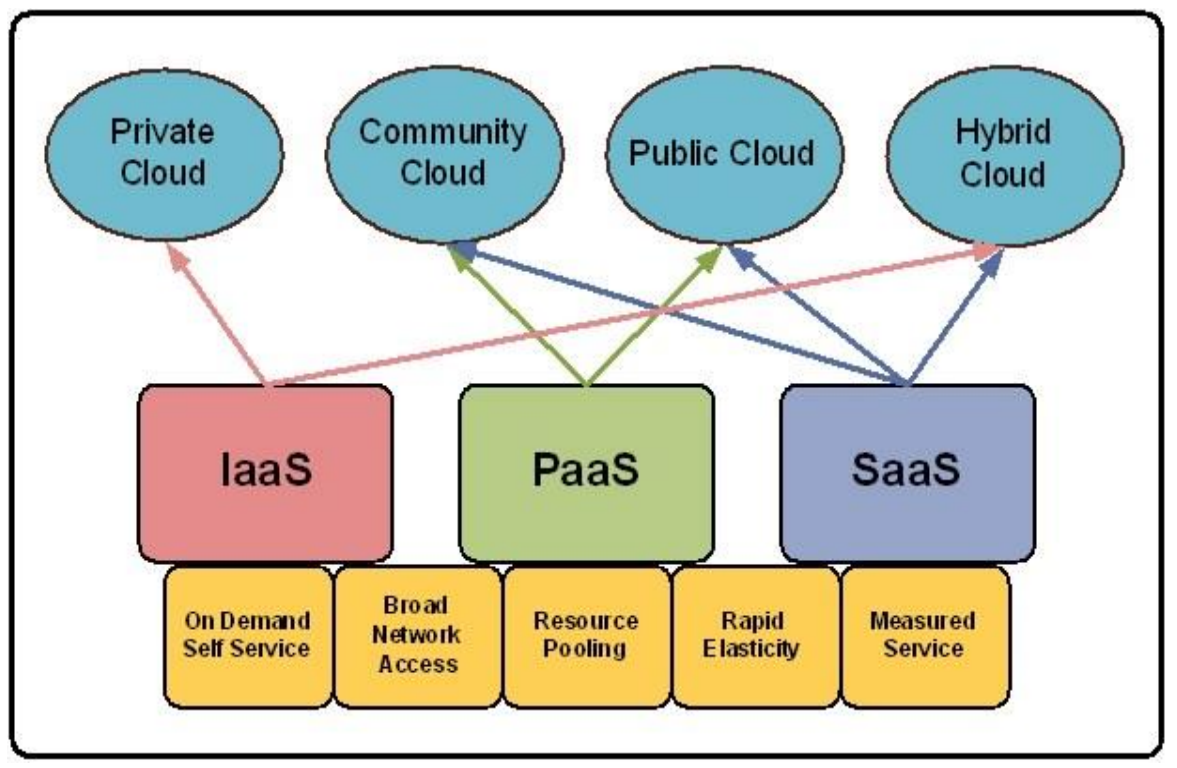

Figure 1. The connections between cloud computing service and deployment models (source (5)).

The methods of delivery that are formed in 4 models can be seen in the figure 1. Business organizations take advantages of these models and services. But there is a problem concerning the preparation of people to work in cloud environments. The question is what competencies they must have in order to be prepared to work in such an environment to be competitive in the labor market in the coming years. $(5,6)$

\section{Some facts}

Recently we are facing facts that we should pay attention when we think about education of new generation of students:

* New professions appear and students must be prepared to practice them nevertheless what specialty they have. Most of the new professions we cannot imagine but we must be sure they are connected with work in cloud computing environment. Even software developers work yet in such environment.

* There are lack of 509000 ICT specialists in EU for the current year 2015.

* In EU countries there are 18000 work places not occupied because of lack of competences and skills for work with cloud computing.

* Most of companies migrate to cloud services which means their stuff will work in a new environment.

In 2012 IDC estimates the growth of cloudrelates IT jobs till the end of 2015. (6) The prediction about Europe, the Middle East and Africa is 1.4 million cloud-related IT jobs with growth of $24 \%$ per year. But for the region of Asia Pacific is more than 2.3 million, result of $32 \%$ growth per year. $(7,8,9)$ It is clear that for all working people the acquiring skills and knowledge for the cloud computing it is of great importance.

\section{User's competencies in the area of cloud computing}

It would be very naïve to think that cloud computing is very easy for usage and people do not need of any special education to deal with. It is obvious that users have to change at least their way of thinking about Web services. Understanding how the cloud computing work could unsure an efficient and productive work. Even we have not mention about innovative ways of working.

The users' competences in cloud computing we found as important are listed below:

* Working with remote services in Internet;

* Co-working with different types of documents;

* Data and files sharing;

* Screen sharing;

* Knowledge and skill for usage of digital repositories;

* Acquiring of main terms and concepts of cloud computing.

\section{OUR SURVEY}

A survey about cloud computing services is organized for determining the level of competencies and knowledge of students in Trakia University, Stara Zagora, Bulgaria. A research of available in Internet quizzes about cloud computing is made in order to facilitate the creation of a new one, appropriate for our students. The quiz is offered via google services and also via paper copies for some students. 
The 24 questions are grouped in 5 categories: data about the student; main terms; cloud computing services models; deployment models and main vendors.

54 students participated in the survey, with age since 18 till 41. Women are 39, and men -15 , which is normal for the gender ratio in our University. After first time of doing the quiz for 23 of the students a lection about cloud computing was offered. These students did the quiz twice and their second results are $50 \%$ better than first ones. (This fact proves the role of the teaching new ICT.) In the end statistical data processing only the data from their first results are taken.
Statistical significant deference between two genders is not observed.

For each of 24 questions statistical distribution of possible answers is made via IBM SPSS package. Pie diagrams are obtained like given in the figure 2, where the results connected with the question number $5(5 \mathrm{~V})$ are presented. The 5th question is "What does the word cloud mean in the term cloud computing?" The right answer is " $\Gamma$ " in Cyrillic. Only $23.64 \%$ of the students have correct knowledge about the meaning of the cloud computing as services available in Internet.

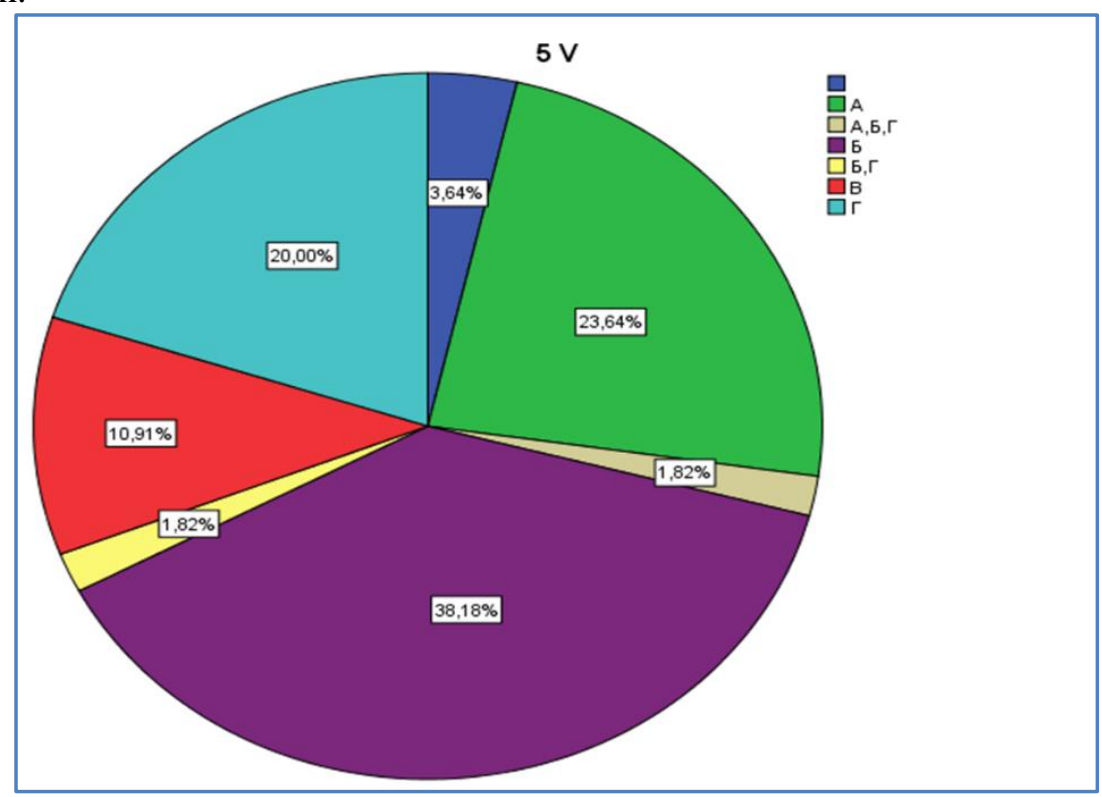

Figure 2. The distribution of answers to $5^{\text {th }}$ question

The alternative type of question with two possible answers True or False gave the advantage of Internet necessary environment for cloud computing work.

The interesting result is that $72 \%$ of the students are familiar with Google Docs as a cloud computing service. This is explainable with some lessons in secondary grade on coworking during Informatics (Computer science) course. The worse result is connected with the question "What is replaced by cloud computing?". Only $2 \%$ of answers are correct. Better percent of correct answers is given about cloud computing platforms $-27 \%$.

The students are not familiar with models of services and deployment of cloud computing. They do not distinguish and understand them. $14 \%$ correct answers are not good result.

Main vendors of cloud computing services are not known. $34 \%$ of the students do not associate Amazon with cloud services, $20 \%$ -
Google and 14\% - Microsoft. Amazon Web Services, Google App Engine and Zoho are not known like cloud services.

\section{CONCLUSIONS}

The technologies change the way world business work. Next years all kinds of specialist will need to possess knowledges and skills for working in the "cloud". This is why the students' ICT competences need to be extended into direction of cloud computing. This should be a very supportive part of their professional preparation that could facilitate all rests.

New disciplines or at least some news topics should be included in the study program together with practical exercises in cloud computing.

\section{REFERENCES}

1. http://www.economy.bg/world/view/15983/ Vsyaka-5-ta-kompaniya-v-ES-izpolzvaoblachni-uslugi, Accessed 03.09.2015 
2. Cloud computing services used by one out of every five enterprises in the EU28, http://ec.europa.eu/eurostat/documents/299 5521/6208098/4-09122014-APEN.pdf/627ddf4f-730a-46ca-856b$32532 \mathrm{~d} 8325 \mathrm{c} 5$

3. Internet usage by individuals in 2014 , Use of cloud services by individuals, 2014, http://ec.europa.eu/eurostat/documents/299 5521/6343581/4-16122014-BPEN.pdf/b4f07b2a-5aee-4b91-b01765bcb6d95daa, Assessed 03.09.2015

4. https://en.wikipedia.org/wiki/Cloud_compu ting

5. The Higher ED CIO, Cloud or Not: 4 Cloud Deployment Models, http://blog.thehigheredcio.com/2011/02/22/ cloud-deployment-models/, Accessed 03.09.2015

6. Saroj Kar, 2013, IDC Report: 1.7 Million Cloud Computing Jobs Remain Unfilled,
Gap Widening,

http://cloudtimes.org/2013/01/09/idcreport-1-7-million-cloud-computing-jobsremain-unfilled-gap-widening/

7. Andl Mann, 6 core competencies to use and provide enterprise cloud services, https://blogs.ca.com/2012/01/17/6-corecompetencies-to-use-and-provideenterprise-cloud-services/ , Accessed 03.09.2015

8. Irmee Layo, 2013, Future of Cloud Computing Projects and Skills Competency Analysis, http://cloudtimes.org/2013/11/19/future-ofcloud-computing-projects-and-skillscompetency-analysis/

9. Florence de Borja, 2013, Cloud Computing Skills Required for IT Employees, http://cloudtimes.org/2013/02/06/cloudcomputing-skills-required-for-it-employees/ 